\title{
Household satisfaction with a community-based health insurance scheme in Ethiopia
}

\author{
Abebe Sorsa Badacho ${ }^{1 *}$, Kora Tushune ${ }^{2}$, Yohannes Ejigu² and Tezera Moshago Berheto ${ }^{1}$
}

\begin{abstract}
Background: Community-based health insurance (CBHI) schemes are an emerging tool for providing financial protection against health-related poverty. In Ethiopia, CBHI is being piloted in 13 districts, but community experience and satisfaction with the scheme have yet to be studied. Therefore, this study aimed to assess the experiences and satisfaction of households enrolled in a pilot CBHI scheme.

Methods: A community-based cross-sectional study method was used in one pilot district in South Ethiopia. Data were collected in March and April 2014. 386 households enrolled in the CBHI scheme were sampled by simple random sampling. Data were collected by trained data collectors using a pre-tested structured questionnaire. Descriptive statistics and bivariate and multiple linear regression analyses were performed. P values less than 0.05 and $95 \%$ confidence intervals were used to determine associations between independent and dependent variables.

Results: The study revealed that overall household satisfaction with CBHI was $91.38 \%$. Moreover, there was a significant association between health service provision and CBHI members'satisfaction scores. For instance, household heads that strongly disagreed with laboratory services provision had an average 0.878 decrease in CBHI satisfaction score compared to household heads that strongly agreed. CBHI process- and management-related factors were also significantly associated with satisfaction.

Conclusions: Satisfaction with CBHI was high. Age, family size, laboratory services provision, health services provider friendliness, CBHI offices opening times, membership card collection process, and time interval to use of services were significant predictors of satisfaction with $\mathrm{CBHI}$.
\end{abstract}

Keywords: Community-based health insurance, Satisfaction score, Pilot district, Ethiopia

\section{Background}

Low-income countries face considerable challenges in financing healthcare [1-3]. Public services are unavailable and unaffordable to the majority of poor people in these countries [4]. Millions of people in developing countries still suffer and die from health-related conditions for which effective but underutilized interventions exist, particularly in settings that lack effective health insurance policies [5]. Health spending via out-of-pocket payments (OOPs) is difficult for many people, and 100

\footnotetext{
${ }^{*}$ Correspondence: sorsabebe@gmail.com

${ }^{1}$ School of Public Health, College of Health Sciences, Wolaita Sodo University, P.O. Box 138, Sodo, Ethiopia

Full list of author information is available at the end of the article
}

million people descend into poverty due to the need to pay for healthcare [6]. Health insurance can be a complementary or alternative source of healthcare finance [7] that has been implemented as part of health reform programs and strategies that aim to provide effective and efficient healthcare, in particular to the poor and vulnerable [8].

Several health insurance strategies can be used for prepayment and universal coverage [9]. Most developed countries use tax-based systems, social health insurance systems, or mixed systems to achieve universal coverage [10]. Community-based health insurance (CBHI) schemes are an emerging and growing tool for providing financial protection to deprived individuals against 
health-related events. CBHIs have the following characteristics: voluntary membership, a non-profit objective, they are linked to a healthcare provider, they pool risk, and there is an underlying ethic of mutual aid trust, enrollment, and solidarity $[11,12]$.

Over 150 million people face catastrophic health expenditures each year, and most fall into poverty due to OOPs [13]; health problems and their associated costs are clearly an important cause of poverty, especially in countries that rely on OOPs [14]. In $60 \%$ of countries with incomes below $\$ 1000$ per capita, OOP spending constitutes over $40 \%$ of total public healthcare expenditure [13]. About 1.3 billion people on very low incomes still lack access to effective and affordable drugs, surgeries, and other interventions due to weaknesses in health financing [15]. An absence of any form of health insurance increases the risk of poverty due to high healthcarerelated costs. As the result, households may leave illness untreated or opt for the use of poor quality healthcare or self-administered medication [16]. Governments of low-income countries face the challenge of reducing the regressive burden of OOP expenditure by expanding prepayment schemes that spread financial risk and reduce the spectrum of catastrophic healthcare expenditure [14].

Due to only limited access to a well-developed health insurance system, about $80 \%$ of private health expenditure in Ethiopia is via OOPs and only $1.5 \%$ of private healthcare expenditure is covered by private insurance institutions [17]. Providing healthcare to individuals working informally or who live in rural areas is a major challenge in developing countries $[18,19]$. CBHI schemes are considered useful in addressing this problem. By pooling risks and resources, CBHIs promise better access to healthcare and risk protection for poor households against the cost of illness [20]. A national implementation pilot CBHI scheme was started in Ethiopia in mid-2011. As a starting point, thirteen districts were selected in four major regional states in Ethiopia for implementation of the pilot scheme. The aim was to reduce financial barriers and improve access to health services by reducing the burden of OOP expenditure [21]. The pilot program scheme covered both outpatient and inpatient healthcare services in public facilities with the aim of enhancing access to healthcare. The experiences and satisfaction of households enrolled in this pilot CBHI scheme is unknown. Therefore, this study focuses on the experiences and satisfaction of households in one of the pilot CBHI scheme districts in Ethiopia.

\section{Methods}

\section{Study design}

A community-based cross-sectional study was conducted in March and April 2014 in Damotwoyde district, 1 of the 13 districts selected for the CBHI pilot project.
Damotwoyde district is located in the Wolaita zone in the Southern Nation Nationalities and Regional State of Ethiopia. The district has 23 rural kebeles (the lowest administrative unit in Ethiopia) and an estimated total population of $116,994.50 \%$ of the households in the district were enrolled in the $\mathrm{CBHI}$ pilot scheme. The district has four health centers and 25 health posts. The health coverage of the district was $92 \%$ in 2014.

\section{Sample size determination}

Sample size was calculated using Epi Info version 7 software using the single population proportion formula. Assuming $50 \%$ of households enrolled in the CBHI scheme were satisfied with CBHI, a confidence level of $95 \%$, a 0.05 margin of error, and a $10 \%$ non-response rate, the final sample size was 392 .

\section{Sampling technique}

All the districts selected for the pilot CBHI scheme were listed with the help of national CBHI agency officials. One of the 13 districts enrolled in the pilot CBHI scheme was selected by simple random sampling (Damotwoyde district). The total number of households enrolled in the pilot CBHI scheme in the selected district was identified using their individual enrolment identification numbers from registration book, and a total of 8008 households enrolled in the CBHI scheme; simple random sampling was used to obtain the final study participants registration book list as a frame.

\section{Data collection and quality assurance}

A structured questionnaire was produced in English and translated from English to the local language. Another translator then translated the local version back into English to check for consistency of meaning. The study variables were adopted from the relevant literature.

The primary respondents were the household heads. Interviewer-administered face-to-face interviews were conducted using structured and pre-tested questionnaires. The data collectors were diploma holders who fluent in the local language. Data collectors were given 3 -days training on the study objectives, method of data collection, and the tools for data collection. The supervisors were senior public health experts. The data collection tool was pre-tested in rural kebeles other than the study area; based on these results, adjustments were made to the data collection tool. Spot checks on the quality of data collection were made in the field and completed questionnaires were checked daily.

\section{Data analysis}

Data were entered into EpiData version 3.1 and exported to SPSS version 20.0 for further analysis. The frequency 
distribution of all the variables was examined to check for data entry errors. Principal component extraction with eigen values greater than 1 and varimax rotation methods were employed for factor analysis. Items with Cronbach's alpha values greater than 0.7 extracted from each of the scales were used in subsequent analyses. When the scales had more than one factor extracted, the factors were renamed according to the items contained in the extracted item. The item mean score and mean score of the scales were computed for those in Likert scale format. The factor score was computed for outcome variables and used for multiple linear regression. Variables showing a statistically significant association in bivariate analysis were analyzed using the enter method of multiple linear regression to examine associations between explanatory variables and the dependent variable. $95 \%$ confidence intervals, and beta coefficients were calculated and used to describe statistically significant variables. A p value $<0.05$ was considered statistically significant.

\section{Measurements Level of satisfaction: overall level of satisfaction with CBHI scheme}

Six items related to satisfaction on a five point Likert scale (from 1: strongly disagree 1 to 5 : strongly agree) were used to assess household heads' satisfaction with CBHI. Together, all six items produced a maximum score of 30 and a minimum score of 6 .

\section{Health service-related factors}

Household heads were asked four questions related to different aspects of service provision. Each question was scored on an ordinal scale from 'strongly disagree' to 'strongly agree' to yield a maximum score of 20 and a minimum score of 4 . These four items were based on the following questions: satisfied with laboratory services; can get immediate care when visiting health facility; respect from service providers; services providers are friendly. The reliability coefficient (Cronbach's alpha) of the health services-related factors scale was 0.851 indicating internal consistency.

\section{CBHI process-related factors}

Household heads were asked four questions on different aspects of CBHI process management on an ordinal scale from 'strongly disagree' to 'strongly agree' to yield a maximum score of 20 and a minimum score of 4 . These four items were based on the following questions: I am satisfied with the opening hours of the CBHI office; I am satisfied with the collection process of insurance cards; I am satisfied with the time to make use of the CBHI program after payment of registration fee; and I am satisfied with the schedule for paying the premium. The reliability coefficient (Cronbach's alpha) of the CBHI process management factors scale was 0.868 indicating internal consistency.

\section{Outcome variables}

The household heads' overall satisfaction with the CBHI program was considered as an outcome variable. Six items related to satisfactions on a five point Likert scale were used to assess respondents' satisfaction with $\mathrm{CBHI}$ to yield a maximum score of 30 and a minimum score of 6. These six items were based on the following questions: local CBHI management trustworthy; satisfied with information provided; satisfied with benefit packages; do not want to stay enrolled (inversely recoded) in the scheme; being enrolled in the scheme did not benefit the household because we are still spending on healthcare (inversely recoded); and recommending CBHI scale up to other settings (considered good if non-members become member of a CBHI scheme). Negatively stated questions were inversely recoded. To examine the underlying factors, an exploratory factor analysis was conducted, which produced one meaningful factor with an eigen value greater than one. This factor accounted for $60 \%$ of the total variance and was renamed as the CBHI member's satisfaction score; thus, the remaining scale items were discarded in linear regression.

Ethical approval Ethical approval was obtained from the ethical clearance board of Jimma University with reference number RPGC/445/2014. The participants were informed about the purpose of the study and oral consent 'was obtained from each study participant prior to conducting the interview.

\section{Results}

Socio demographic characteristics of the respondents

Three hundred and eighty-six household heads participated in the study, producing a response rate of $98.4 \%$. Of these, 292 (75.6\%) were male. The median (interquartile range (IQR) age of participants was 44 (38.54) years. The majority of participants $(274 ; 70.3 \%)$ were married with one spouse. The median household size was 6 , and 235 (60.9 \%) had over five family members. Over half (206; $53.4 \%)$ of participants were protestant. Nearly three-fifths and one in four participants were unable to read and write and attended primary school, respectively. $84.5 \%$ (326) of participants were farmers. The estimated mean family income per annum as reported by respondent was 268.23 (SD \pm 5.67) USD (Table 1).

\section{Experiences of participants in the pilot $\mathrm{CBHI}$ scheme}

All participants reported that at least one family member had fallen sick and had visited a healthcare institution during their illness since enrolment in the $\mathrm{CBHI}$ 
Table 1 Socio-demographic characteristics of the participants, South Ethiopia, $2014(n=386)$

\begin{tabular}{lrc}
\hline Variables & Frequency & Percent \\
\hline Sex of house hold heads & 292 & 75.6 \\
Male & 94 & 24.4 \\
Female & & \\
Age & 191 & 49.4 \\
25-44 & 147 & 38.1 \\
45-64 & 46 & 11.9 \\
$>64$ & & \\
Marital status & 299 & 77.4 \\
Married & 87 & 22.5 \\
Single & & \\
Family size & 151 & 39.1 \\
1-5 members & 235 & 60.9 \\
Greater than 5 & & \\
Religion & 206 & 53.4 \\
Protestant & 120 & 31.1 \\
Orthodox & 60 & 15.5 \\
Catholic & & \\
Educational status & 236 & 61.1 \\
Not able to read and write & 38 & 9.8 \\
Able to read and write & 96 & \\
Grade 1-8 & & \\
Grade 9 and above & & \\
\hline
\end{tabular}

scheme. About $80 \%$ of household members who fell sick visited health centers within the district with a contractual agreement with the CBHI scheme; the remainder were referred to the nearest public hospital with an agreement with the CBHI scheme. Over $84 \%$ of households visited healthcare institutions more than twice after scheme enrolment. Three quarters (290) of households reported that their decision to enroll as a member of the CBHI scheme was made by themselves. All respondents reported that they paid the membership fees.

Community-based health insurance members were required to visit public health centers within the district or the nearest public hospitals with an agreement with the CBHI scheme. Almost $98.2 \%$ of household heads reported that they were happy with the permitted healthcare institutions. During their visits to healthcare institutions, $372(96.4 \%)$ of household heads received the correct prescribed drugs and 360 $(93.3 \%)$ reported that they received the requested laboratory services.

With respect to perceived service quality, 379 (98.2 \%) participants perceived that the quality was good compared to their past experiences prior to CBHI. Similarly,
379 (98.2 \%) participants reported that CBHI enrolment had benefited their household members. 304 (78.7 \%) household heads had experience participating in a CBHIrelated meeting.

\section{Description of CBHI members' satisfaction with the CBHI scheme}

All household heads responded that they either agreed or strongly agreed in recommending CBHI scale-up to other settings. Almost all (97.8\%) respondents agreed or strongly agreed that scheme enrollment had benefited their households, while $376(97 \%)$ agreed or strongly agreed to stay enrolled in the scheme. Ninetytwo percent of respondents responded that they either agreed or strongly agreed with local CBHI managers' trustworthiness.

\section{Level of satisfaction with the $\mathrm{CBH}$ scheme}

To determine the overall level of satisfaction with the CBHI scheme, internal consistency (Cronbach's alpha) was first calculated for the scale items measuring satisfaction: the items had a Cronbach's alpha of 0.861. The mean satisfaction was $27.93 \pm 1.98$ (possible range 6-30). The percentage mean (SD) satisfaction score was calculated based on the percentage of maximum scale score. Accordingly, the overall level of members' satisfaction (percentage mean score) with CBHI was $91.38 \pm 8.24$.

\section{Socio demographic predictors of members' satisfaction with the $\mathrm{CBHI}$ scheme}

Socio demographic variables explained only $7.7 \%$ of satisfaction score variability. Accordingly, age, family size, and estimated annual income were statistically associated with satisfaction score. The CBHI members' satisfaction score increased by an average of 0.011 units with age change in one year ( $95 \%$ CIs 0.002 to 0.02 ). An average increase in family size decreased the satisfaction score by an average of -0.074 units $(\mathrm{p}<0.05)$, with estimated annual income having no effect (Table 2).

\section{Experiences of households since CBHI enrollment as a determinant of $C B H I$ members' satisfaction}

Variables related to CBHI members' experiences were entered into the model. This model explained $14.8 \%$ of the variation in satisfaction among household heads within the CBHI scheme. Households who had paid the premium three times had an average decrease of 0.58 in CBHI satisfaction compared to households who paid the premium over three times $(\mathrm{p}<0.05)$. Households who paid the premium twice a year had an average decrease of 0.32 in CBHI satisfaction compared to households that paid monthly ( $\mathrm{p}<0.05$; Table 3$)$. 
Table 2 Socio-demographic determinants of CBHI members' satisfaction of the CBHI scheme, South Ethiopia, 2014

\begin{tabular}{|c|c|c|c|c|}
\hline Socio-demographic variables & No. (\%) & p value & Unstandardized B coefficient & $95 \%$ Cls for $\mathrm{B}$ \\
\hline \multicolumn{5}{|l|}{ Sex of household heads } \\
\hline Male & $292(75.6)$ & 0.867 & -0.043 & -0.541 to 0.456 \\
\hline Female $^{a}$ & $94(24.4)$ & & & \\
\hline Age & & $0.021^{* *}$ & 0.011 & 0.002 to 0.02 \\
\hline \multicolumn{5}{|l|}{ Marital status } \\
\hline Married with one spouse $\mathrm{a}^{\mathrm{a}}$ & $274(71)$ & & & \\
\hline Married with more than 1 & $25(6.5)$ & 0.762 & 0.064 & -0.351 to 0.480 \\
\hline Separated/divorced & $13(3.3)$ & 0.175 & -0.467 & -1.144 to 0.209 \\
\hline Widowed & $74(19.2)$ & 0.357 & 0.250 & -0.283 to 0.78 \\
\hline Family size & & $0.008^{* * *}$ & -0.074 & -1.29 to -0.02 \\
\hline \multicolumn{5}{|l|}{ Religion } \\
\hline Protestant $^{a}$ & $206(53.4)$ & & & \\
\hline Orthodox & $120(31.1)$ & 0.11 & 0.188 & -0.043 to 0.418 \\
\hline Catholic & $60(15.5)$ & 0.11 & 0.235 & -0.053 to 0.524 \\
\hline \multicolumn{5}{|l|}{ Education } \\
\hline Not able to read and write ${ }^{\mathrm{a}}$ & $236(61.1)$ & & & \\
\hline Able to read and write & $38(9.8)$ & 0.775 & 0.051 & -0.299 to 0.041 \\
\hline Grade 1-8 & $96(24.9)$ & 0.157 & 0.180 & -0.069 to 0.429 \\
\hline Grade 9 and above & $15(4.2)$ & 0.71 & 0.097 & -0.416 to 0.610 \\
\hline \multicolumn{5}{|l|}{ Household head's occupation } \\
\hline Farmer $^{\mathrm{a}}$ & $326(84.5)$ & & & \\
\hline Merchant & $23(6)$ & 0.264 & -0.252 & -0.695 to 0.191 \\
\hline Housewife & $37(9.6)$ & 0.304 & 0.238 & 0.693 to 0.217 \\
\hline Estimated annual income & & $0.003^{* * *}$ & 7.359 & 0.000 to 0.00 \\
\hline
\end{tabular}

${ }^{a}$ References category (categories with highest frequency taken as reference categories)

*** Significant at $p<0.001, * *$ significant at $p<0.05, r^{2}=7.7 \%$

\section{Health service provision-related determinants of $\mathrm{CBHI}$ members' satisfaction with the CBHI scheme}

Variables related to health service provision were entered into the model. This model explained $19.2 \%$ of the variation in satisfaction among household heads in the CBHI scheme. Respondents who strongly disagreed that they were satisfied with laboratory services provision had a 0.88 average decrease in CBHI satisfaction score compared to household heads who were strongly agreed $(\mathrm{p}<0.001)$. Furthermore, household heads who strongly disagreed with service providers' friendliness had an average decrease of 0.82 in the $\mathrm{CBHI}$ satisfaction score compared to household heads who were strongly agreed ( $<<0.001$; Table 4).

\section{$\mathrm{CBHI}$ process and management-related determinants of $\mathrm{CBHI}$ members' satisfaction}

Variables related to CBHI process and management were entered into the model. The model explained $32.6 \%$ of the variation in satisfaction in household heads enrolled in the CBHI scheme. The card collection process, CBHI office opening times, time interval to use benefits, and paying the premium were all significantly associated with member satisfaction (Table 5).

Household heads who disagreed with CBHI office opening times had an average $1.578 \mathrm{CBHI}$ satisfaction score decrease compared to household heads that were strongly agreed $(\mathrm{p}<0.001)$, while household heads who agreed had an average decrease of 0.258 in the satisfaction score compared to those who strongly agreed ( $\mathrm{p}<0.01)$. Two hundred and sixty $(67.4 \%)$ household heads responded that they strongly agreed with the card collection process. Household heads that agreed had an average decrease of 0.52 in satisfaction score compared to those who strongly agreed $(\mathrm{p}<0.01)$. Household heads who were neutral for satisfaction with the time taken after registration and use of the services or waiting time as a mechanism to reduce or control adverse selection of CBHI members had an average decrease of 3.281 compared to household heads who were strongly agreed $(\mathrm{p}<0.01)$. Three hundred and seventy-three (96.6\%) household heads responded that they strongly agreed or agreed with paying membership premium and those that agreed had a 0.295 
Table 3 Different experiences of $\mathrm{CBHI}$ as determinants of CBHI members' satisfaction with the scheme, South Ethiopia, 2014

\begin{tabular}{|c|c|c|c|c|}
\hline $\begin{array}{l}\text { Different expe- } \\
\text { riences }\end{array}$ & No. (\%) & $p$ value & $\begin{array}{l}\text { UnstB coef- } \\
\text { ficient }\end{array}$ & $95 \%$ Cls for B \\
\hline \multicolumn{5}{|c|}{ Voluntary enrolment in the $\mathrm{CBH}$} \\
\hline$Y_{e s}{ }^{a}$ & 310 & & & \\
\hline No & 76 & $0.036^{\mathrm{a}}$ & -0.298 & -0.58 to -0.02 \\
\hline \multicolumn{5}{|c|}{ Got prescribed drugs } \\
\hline$Y_{e s}^{\mathrm{a}}$ & 372 & & & \\
\hline No & 14 & 0.563 & -0.173 & -0.76 to 0.41 \\
\hline \multicolumn{5}{|c|}{ Got requested laboratory services } \\
\hline$Y_{e s}^{a}$ & 360 & & & \\
\hline No & 26 & 0.290 & -0.260 & -0.74 to 0.22 \\
\hline \multicolumn{5}{|c|}{ Satisfied with visited healthcare institution } \\
\hline Yes $^{\mathrm{a}}$ & 375 & & & \\
\hline No & 11 & 0.667 & -0.174 & -0.97 to 0.62 \\
\hline \multicolumn{5}{|c|}{ CBHI benefited households } \\
\hline Yes $^{\mathrm{a}}$ & 379 & & & \\
\hline No & 7 & $0.003^{* *}$ & -1.25 & -2.00 to -0.42 \\
\hline \multicolumn{5}{|c|}{ Participation of CBHI-related meeting } \\
\hline$Y_{e s}{ }^{a}$ & 304 & & & \\
\hline No & 82 & 0.49 & -0.33 & -1.30 to 0.64 \\
\hline \multicolumn{5}{|c|}{ Discussion with $\mathrm{CBHI}$ managers } \\
\hline$Y_{e s}^{a}$ & 300 & & & \\
\hline No & 86 & 0.89 & 0.07 & -0.90 to 1.00 \\
\hline \multicolumn{5}{|c|}{ Times premium paid } \\
\hline Once & 10 & 0.61 & -0.156 & -0.76 to 0.45 \\
\hline Twice & 37 & 0.95 & 0.011 & -0.32 to 0.35 \\
\hline 3 times & 64 & $0.001^{* *}$ & -0.578 & -0.84 to -0.32 \\
\hline$>3$ times $^{\mathrm{a}}$ & 275 & & & \\
\hline \multicolumn{5}{|c|}{ Times healthcare visited } \\
\hline Once & 59 & 0.36 & 0.14 & -0.16 to 0.43 \\
\hline Twice & 98 & 0.98 & 0.003 & -0.25 to 0.25 \\
\hline 3 times & 91 & 0.53 & 0.08 & -0.18 to 0.34 \\
\hline$>3$ times $^{a}$ & 138 & & & \\
\hline \multicolumn{5}{|c|}{ Schedule of payment } \\
\hline Monthly $^{a}$ & 255 & & & \\
\hline Quarterly & 60 & 0.154 & -0.202 & -0.48 to 0.07 \\
\hline Twice per year & 62 & $0.024^{\mathrm{a}}$ & -0.320 & -0.59 to -0.04 \\
\hline Once a year & 9 & 0.503 & -0.218 & -086 to 0.422 \\
\hline
\end{tabular}

a Reference group

*** significant at $\mathrm{p}<0.001,{ }^{* *}$ Significant at $\mathrm{p}<0.05$

decrease in satisfaction score compared to those who strongly agreed $(\mathrm{p}<0.01)$.

\section{Predictors of $C B H I$ members' satisfaction with $C B H I$}

Multivariable regression was performed for significant variables in bivariate analysis to produce a final model for $\mathrm{CBHI}$ scheme satisfaction. Accordingly, age, time premium paid, laboratory services provision, health services provider friendliness, CBHI office opening time, card collection process, time interval, and use of services (waiting period to control adverse selection of members) were found to be strong predictors.

On average, an increase in family size produced an average decrease of 0.047 in their satisfaction score (95\% CIs -0.09 to -0.005$)$, while 1-year increase in household head age increased satisfaction by0.09 ( $p<0.05$ ). Household heads that strongly disagreed with laboratory services provision had an average decrease of 0.13 units in satisfaction compared to household heads who agreed $(\mathrm{p}<0.05)$. Household heads who strongly disagreed with service provider friendliness had an average decrease of 0.12 units in satisfaction $(\mathrm{p}<0.05)$, while those that disagreed with local CBHI scheme office opening times had an average decrease of 0.16 units in satisfaction compared to those who strongly agreed $(\mathrm{p}<0.001)$. Similarly, household heads that agreed with the membership card collection process had a decrease of 0.18 units in satisfaction score compared to those who strongly agreed ( $<<0.001$; Table 6).

\section{Discussion}

Establishing health insurance services is gaining traction in resource-limited countries to improve health care utilization and ensure financial protection for households to mitigate against poverty induced by OOPs. Despite this, the impact of health insurance in low and middle-income countries is, unfortunately, poorly documented.

Here we show that household satisfaction with a CBHI scheme implemented in Ethiopia was high (Fig. 1). In 2005, the World Health Assembly called on all countries to move towards universal health coverage, especially in developing countries with huge inequalities in health service delivery $[22,23]$. Thus, the overall high satisfaction rate shown here may help and encourage scale up of the CBHI scheme to the remainder of the community and enhance universal health coverage (UHC). There is evidence that $\mathrm{CBHI}$ increases healthcare utilization [12]. In this study, age was associated with CBHI satisfaction; in a similar study in Nigeria, older clients were more satisfied with service provision than younger clients [24]. This might be attributed to more frequent illness in elderly people. However, other variables such as occupation, education, marital status, sex, and income were not significant predictors, consistent with studies conducted in India on national health insurance satisfaction, who also found no differences in satisfaction across socioeconomic and demographic variables [3]. Conversely, a Turkish study of patient satisfaction of national health insurance showed that there was a significant relationship between 
Table 4 Health services provision-related determinants of CBHI members' satisfaction of CBHI scheme, South Ethiopia, 2014

\begin{tabular}{|c|c|c|c|c|}
\hline Variables & No. (\%) & $P$ value & Unstandardized B coefficient & $95 \%$ Cls for B \\
\hline \multicolumn{5}{|c|}{ Satisfied with laboratory services } \\
\hline Strongly disagree & $17(4.4)$ & $0.000^{* *}$ & -0.88 & -1.34 to -0.42 \\
\hline Disagree & $17(4.4)$ & $0.012^{* *}$ & -0.59 & -1.06 to -0.13 \\
\hline Neutral & $6(1.6)$ & 0.07 & -0.67 & -1.423 to 0.08 \\
\hline Agree & $163(42.20)$ & 0.07 & -0.19 & -0.39 to 0.02 \\
\hline Strongly agree ${ }^{a}$ & $183(47.4)$ & & & \\
\hline \multicolumn{5}{|c|}{ Services providers friendly } \\
\hline Strongly disagree & $43(11.1)$ & $0.000^{* * *}$ & -0.82 & -1.13 to -0.51 \\
\hline Disagree & $37(9.6)$ & $0.000^{* * *}$ & -0.78 & -1.10 to -0.45 \\
\hline Neutral & $9(2.3)$ & $0.000^{* * *}$ & -1.16 & -1.77 to -0.54 \\
\hline Agree & $95(24.6)$ & $0.000^{* * *}$ & -0.33 & -0.57 to -0.09 \\
\hline Strongly agree ${ }^{a}$ & $202(52.3)$ & & & \\
\hline
\end{tabular}

${ }^{a}$ Reference category

*** Significant at $p<0.001,{ }^{* *}$ significant at $p<0.05, r^{2}=19.2 \%$

Table 5 CBHI process and management-related determinants of satisfaction with CBHI scheme, South Ethiopia, 2014

\begin{tabular}{|c|c|c|c|c|}
\hline Variables & No (\%) & $P$ value & Unstandardized B coefficient & $95 \% \mathrm{Cl}$ for $\mathrm{B}$ \\
\hline \multicolumn{5}{|c|}{ Happy with CBHI offices opening times } \\
\hline Strongly disagree & $4(1)$ & 0.606 & 0.220 & -0.62 to -1.06 \\
\hline Disagree & $6(1.6)$ & $0.000^{* * *}$ & -1.578 & -2.311 to -0.844 \\
\hline Neutral & $3(.8)$ & 0.789 & -0.225 & -1.883 to -1.433 \\
\hline Agree & $157(40.7)$ & $0.005^{* * *}$ & -0.258 & -0.44 to -0.077 \\
\hline Strongly agree ${ }^{a}$ & $216(56)$ & & & \\
\hline \multicolumn{5}{|c|}{ Satisfaction with members card collection on process } \\
\hline Disagree & $4(1)$ & 0.447 & 0.357 & -0.565 to 1.280 \\
\hline Neutral & $3(.8)$ & 0.063 & 1.200 & -0.066 to 2.466 \\
\hline Agree & $119(30.8)$ & $0.000^{* * *}$ & -0.520 & -0.723 to -0.318 \\
\hline Strongly agree ${ }^{a}$ & $260(67.4)$ & & & \\
\hline \multicolumn{5}{|c|}{ Satisfied with time interval to use benefit package } \\
\hline Disagree & $14(3.7)$ & 0.053 & -0.506 & -1.018 to 0.006 \\
\hline Neutral & $2(0.5)$ & $0.004^{* * *}$ & -3.281 & -5.488 to -1.073 \\
\hline Agree & $91(23.6)$ & 0.567 & -0.066 & -0.294 to 0.161 \\
\hline Strongly agree ${ }^{a}$ & $279(72.3)$ & & & \\
\hline \multicolumn{5}{|c|}{ Satisfied with paying premium } \\
\hline Strongly disagree & $1(.3)$ & 0.239 & -0.999 & -2.664 to 0.667 \\
\hline Disagree & $8(2.1)$ & 0.379 & -0.288 & -0.929 to 0.354 \\
\hline Neutral & $4(1)$ & $0.000^{* * *}$ & -2.705 & -3.758 to -1.653 \\
\hline Agree & $102(26.4)$ & $0.006^{* * *}$ & -0.295 & -0.506 to -0.084 \\
\hline Strongly agree & $271(70.2)$ & & & \\
\hline
\end{tabular}

a Reference category

*** Significant at $p<0.001,{ }^{* *}$ significant at $p<0.05$

satisfaction and gender, marital status, education level, and occupation [25]. This may be due to differences in study design, since the Turkish study was facility based. We also found that an average increase in family size reduced satisfaction with the $\mathrm{CBHI}$ scheme. This may have been due to payment arrangements, since larger families incur additional fees, which must be declared as the family grows in size. 
Table 6 Predictors of CBHI members' satisfaction with CBHI, Damot woyde, Southern Ethiopia April 2014

\begin{tabular}{|c|c|c|c|c|c|}
\hline Variables & No (\%) & $P$ value & Unst B & Stan B & $95 \% \mathrm{Cl}$ for B \\
\hline Age & & $0.03^{* *}$ & 0.007 & 0.09 & 0.001 to 0.015 \\
\hline Family size & & 0.055 & -0.04 & -0.09 & -0.08 to 0.001 \\
\hline Income & & 0.259 & 0.00 & 0.05 & 0.000 to 0.000 \\
\hline \multicolumn{6}{|l|}{ Lab services } \\
\hline $\begin{array}{l}\text { Strong disa- } \\
\text { gree }\end{array}$ & $17(4.4)$ & $0.009^{* * *}$ & -0.58 & -0.12 & -1.01 to -0.15 \\
\hline Disagree & $17(4.4)$ & & 0.02 & 0.05 & -0.40 to 0.45 \\
\hline $\begin{array}{l}\text { Strongly } \\
\text { agree }^{\mathrm{a}}\end{array}$ & $183(47.4)$ & 0.914 & & & \\
\hline \multicolumn{6}{|c|}{ Services provider friendly } \\
\hline $\begin{array}{l}\text { Strongly } \\
\text { disagree }\end{array}$ & $43(11.1)$ & & -0.420 & -0.13 & -0.75 to -0.09 \\
\hline Disagree & $37(9.6)$ & $0.012^{* *}$ & -0.359 & -0.11 & -0.68 to -0.04 \\
\hline Neutral & $9(2.3)$ & $0.03^{* *}$ & -0.903 & -0.136 & -1.45 to -0.35 \\
\hline Agree & $95(24.6)$ & $0.001^{* *}$ & -0.18 & -0.08 & -0.38 to 0.03 \\
\hline $\begin{array}{l}\text { Strongly } \\
\text { agree }^{\mathrm{a}}\end{array}$ & $202(52.3)$ & 0.09 & & & \\
\hline \multicolumn{6}{|c|}{ Happy with CBHI offices working time } \\
\hline Disagree & $6(1.6)$ & $0.001^{* * *}$ & -1.311 & -0.16 & -2.09 to -0.53 \\
\hline Agree & $157(40.7)$ & $0.004^{* *}$ & -0.254 & -0.12 & -0.42 to -0.08 \\
\hline $\begin{array}{l}\text { Strongly } \\
\text { agree }^{\mathrm{a}}\end{array}$ & $216(56.0)$ & & & & \\
\hline \multicolumn{6}{|c|}{ Card collection process } \\
\hline Agree & $119(30.8)$ & $0.001^{* * *}$ & -0.4 & -0.18 & -0.59 to -0.21 \\
\hline $\begin{array}{l}\text { Strongly } \\
\text { agree }^{\mathrm{a}}\end{array}$ & $260(67.4)$ & & & & \\
\hline \multicolumn{6}{|c|}{ Time interval and use } \\
\hline Neutral & $2(.5)$ & $0.001^{* * *}$ & -3.12 & -0.22 & -4.47 to -1.76 \\
\hline $\begin{array}{l}\text { Strongly } \\
\text { agree }^{\mathrm{a}}\end{array}$ & $279(72.3)$ & & & & \\
\hline \multicolumn{6}{|l|}{ Pay premium } \\
\hline Agree & $102(26.4)$ & $0.001^{* * *}$ & -1.83 & -0.19 & -2.71 to -0.95 \\
\hline Neutral & $4(1)$ & $0.04^{* *}$ & -0.31 & -0.12 & -0.54 to -0.09 \\
\hline $\begin{array}{l}\text { Strongly } \\
\text { agree }^{\mathrm{a}}\end{array}$ & $271(70.2)$ & & & & \\
\hline \multicolumn{6}{|c|}{ Voluntary enrollment } \\
\hline$Y_{e s}^{a}$ & 310 & & & & \\
\hline No & 76 & 0.121 & -0.19 & -0.07 & -0.43 to -0.05 \\
\hline \multicolumn{6}{|c|}{ CBHI benefited households } \\
\hline$Y_{e s}^{a}$ & 379 & & & & \\
\hline No & 7 & 0.99 & 0.002 & 0.00 & -0.7 to 0.70 \\
\hline \multicolumn{6}{|c|}{ Schedule of payment } \\
\hline Monthly ${ }^{\mathrm{a}}$ & 255 & & & & \\
\hline $\begin{array}{l}\text { Twice per } \\
\text { year }\end{array}$ & 65 & 0.216 & -0.15 & -0.05 & -0.38 to 0.08 \\
\hline \multicolumn{6}{|c|}{ Times premium paid } \\
\hline 3 times & 64 & $0.007^{* *}$ & -0.31 & -0.12 & -0.54 to -0.08 \\
\hline$>3$ times $^{a}$ & 275 & & & & \\
\hline
\end{tabular}

a Reference category

*** Significant at $\mathrm{p}<0.001,{ }^{* *}$ significant at $\mathrm{p}<0$
We also aimed to identify health service provisionrelated factors that were significantly associated with CBHI satisfaction; good laboratory service provision and health provider friendliness during service provision increased satisfaction with CBHI. This suggests that, and bearing in mind a "chicken or egg" dilemma as a limitation of the study, that satisfaction with involvement in $\mathrm{CBHI}$ increased expectation/satisfaction in laboratory services and provider friendliness. In a similar study in Burkina Faso, CBHI members' poor perception of their healthcare provider was an important reason for dropping out of the Nouna Community Based Insurance scheme [26]. Another study from rural tropical Ecuador found that low healthcare utilization could be an obstacle to successful implementation of a CBHI scheme and was closely associated with the local health services and availability of dedicated and friendly staff and essential drugs [1]. Furthermore, a study on India's national health insurance scheme implied that the services provided by doctors and nurses were slightly less satisfactory [3].

We also found that CBHI process and management were significantly associated with CBHI satisfaction, particularly with respect to $\mathrm{CBHI}$ office opening times, the membership card collection process, waiting time (length of time between registration and use of the service), and amount of payment, which were all positively associated with satisfaction. In a study of Kenya's Kilifi district CBHI scheme, households reported that they were not interested in renewing their membership due to corruption affecting CBHI management and leading to dissatisfaction [27].

Finally, our findings indicate that age, family, laboratory services, service provider friendliness, office opening times, card collection process, time interval to use of services (waiting period), paying the premium, and the number of times the premium was paid were the main predictors of CBHI members' satisfaction with this CBHI scheme.

\section{Study limitation}

This study only focused on the demand side point of view (households who enrolled), and the supply side view (provider side) was not explored.

\section{Conclusions}

Based on these findings, households enrolled in CBHI are highly satisfied and almost all households would recommend expansion of the program to other settings. Rural and informal sectors in particular benefited from this program. Due to their enrollment in the CBHI pilot program, members were able to access healthcare and utilize modern healthcare institutions. Age, family size, frequency of premium paid, laboratory services provision, 


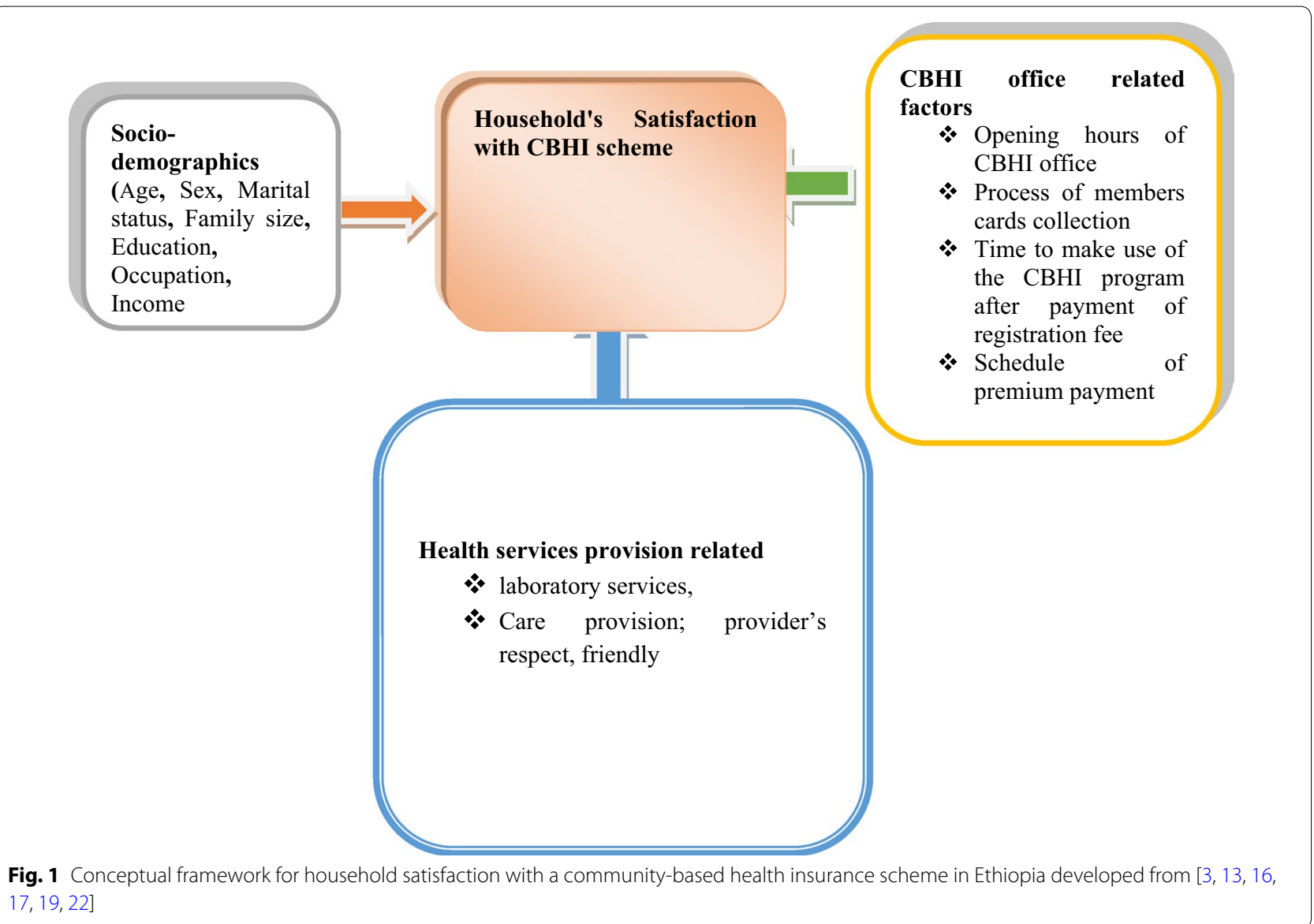

friendliness of health services providers, CBHI office opening times, the membership card collection process, and time interval to use of services were significant predictors of satisfaction with the CBHI scheme.

\section{Recommendation}

To achieve universal health coverage, the Government of Ethiopia is promoting and implementing voluntary CBHI schemes and social health insurance to enhancing healthcare access and reduce the burden of OOP expenditure. This was a study of a pilot CBHI scheme, with promising and encouraging results for rural households. However, we recommend further studies to identify other predictors of CBHI members' satisfaction not addressed here, especially health service provision-related determinants.

\section{Authors' contributions}

AS, KT and YE conception and design of the study and data analysis. TM analyzed the data and interpreted the findings. AS conducted and supervised data collection and management. All authors read and approved the final manuscript.

\section{Author details}

${ }^{1}$ School of Public Health, College of Health Sciences, Wolaita Sodo University, P.O. Box 138, Sodo, Ethiopia. ${ }^{2}$ Department of Health Services Management,
College of Public Health and Medicine, Jimma University, P.O. Box 378, Jimma, Ethiopia.

\section{Acknowledgements}

The author's sincere gratitude goes to the data collectors, supervisors and study participants. The authors also thank Nextgenediting for editorial assistance as part of their Global Initiative.

\section{Competing interests}

The authors declare that they have no competing interests.

Availability of data and material

Dataset generated and analyzed during the study is available as suppository

\section{Ethics and consent to participate}

Ethical approval was obtained from the ethical clearance board of Jimma University with reference number RPGC/445/2014, according to the standardized principle and procedure which in line with national and WHO guideline. The participants were informed about the purpose of the study and oral consent was obtained from each study participant prior to conducting the interview.

Received: 14 November 2015 Accepted: 15 August 2016

Published online: 30 August 2016

References

1. Vialle-Valentin CE, Ross-Degnan D, Ntaganira J, Wagner AK. Medicines coverage and community-based health insurance in low-income countries. Health Res Policy Syst. 2008;6(1):1. 
2. Nevondwe L, Odeku KO. Financing the National Health Insurance Scheme of South Africa: opportunities and challenges. J Soc Sci. 2014;39(1):9-18.

3. Devadasan N, Criel B, Damme WV, Lefevre P, Manoharan S, der Stuyft PV Community based health Insurance and patient satisfaction-evidence from India. Indian J Med Res. 2011;133(1):40-9.

4. Mclntyre D. Learning from experience: Health care financing in low and middle income countries. Geneva: Global Forum for Health Research 2007.

5. Office II: The decent work agenda in Africa: 2007-2015 eleventh African regional meeting addis Ababa, April 2007.

6. Ahoobim O, Altman D, et al. The new global health agenda: Universal health coverage. New York: Council on Foreign Relations; 2012.

7. Awosika L. Health insurance and managed care in Nigeria. Ann lb Postgrad Med. 2007;3(2):40-51.

8. Examples of $\mathrm{CBHI}$ in Central Asia include the revolving drug fund schemes in Armenia, Azerbaijan, and Georgia 2006.

9. Carrin G, James C, Evans DB. Achieving universal health coverage: developing the health financing system. Geneva: World Health Organization; 2005

10. Fonteneau B, Galland B: The community-based model: mutual health organizations in Africa. In: Churchill C, International Labour Office (eds). Protecting the poor: a microinsurance compendium. 2006, xix:654.

11. The Council of the European Union. Laying down minimum standards for the reception of asylum seekers. Off J Eur Union 2003.

12. Derseh A, Sparrow RA, Debebe ZY, Alemu G, Bedi AS. Enrolment in Ethiopia's community based health insurance scheme. ISS Working paper Series/General Series, vol. 578. International Institute of Social Studies of Erasmus University (ISS); 2013, p. 1-35. http://hdl.handle.net/1765/50221.

13. Dror DM, Preker AS. Social reinsurance: a new approach to sustainable community health financing, the World Bank, Washington D.C. 2002.

14. Ataguba JE, Ichoku HE, Fonta WM. Estimating the willingness to pay for community healthcare insurance in rural Nigeria'. Cahiers de recherche PMMA 2008.

15. WHO: 'Global Health observatory Data Repository, World Health Organization Data by Countries; 2012.
16. Preker AS, Carrin G. Health financing for poor people: resource mobilization and risk sharing. World Bank Publications 2004, 434.

17. Bernhat HM, Wiadnyana IGP, Wihardjo H, Pohan I. Patient satisfaction in developing countries. Soc Sci Med. 1999;48:989-96.

18. World Health Organization: strengthening health systems to improve health outcomes. WHO's framework for action; 2007.

19. Guy C, Maria-Pia W, Bart C. Community-based health insurance in developing countries: a study of its contribution to the performance of health financing systems. Tropical Med Int Health. 2005;10(8):799-811.

20. Huber G. Mutual health insurance (MHO): five years experiences in West Africa: health sector reforms in sub-Saharan Africa: lessons of the last 10 years.

21. Kagubare M. The impact of community-based health insurance on health care utilization and financial sustainability: the example of Rwanda. The Johns Hopkins University; 2006.

22. World Health Organization. Sustainable health financing, universal coverage and social health insurance. World Health Assembly Resolution. 2005.

23. Carrin $G$, James $C$. Reaching universal coverage via social health insurance: key design features in the transition period. From http://apps.who. int/iris/handle/10665/69018 on Feb 1, 2015; 2004

24. Mohammed S, Sambo MN, Dong H. Understanding client satisfaction with a health insurance scheme in Nigeria: factors and enrollees experiences. Health Res Policy Syst. 2011;9(1):20.

25. Ahmed Saad, Jadoo Ali, Ezat Sharifa, Zafar A, Ammar J. Level of Patients' Satisfaction toward National Health Insurance in Istanbul City (Turkey). World App Sci J. 2012;17(8):976-85.

26. Robyn PJ, Bärnighausen T, Souares A, Savadogo G, Bicaba B, Sié A, Sauerborn R. Does enrollment status in community-based insurance lead to poorer quality of care? Evidence from Burkina Faso. Inter J Equity Health. 2013;12:31-2.

27. Catherine M, Beryl H, Jane C, Lucy G. The role of community-based organizations in household ability to pay for health caremin Kilifi District, Kenya. Health Policy Plan. 2007;22:381-92.

\section{Submit your next manuscript to BioMed Central and we will help you at every step:}

- We accept pre-submission inquiries

- Our selector tool helps you to find the most relevant journal

- We provide round the clock customer support

- Convenient online submission

- Thorough peer review

- Inclusion in PubMed and all major indexing services

- Maximum visibility for your research

Submit your manuscript at www.biomedcentral.com/submit
( ) Biomed Central 